\title{
In reply: Clarification on: "Pectoral nerves I block is associated with a significant motor blockade with no dermatomal sensory changes"
}

\author{
Jean Desroches, MD, FRCPC • Maxim Roy, MD (1) P Pierre Beaulieu, MD, PhD, FRCA
}

Received: 11 September 2018/Revised: 16 September 2018/ Accepted: 17 September 2018/Published online: 1 October 2018

(C) Canadian Anesthesiologists' Society 2018

\section{To the Editor,}

We thank Dr. M S ${ }^{1}$ for his interest in our paper. ${ }^{2}$ The purpose of our study was to objectively evaluate the ability of the pectoral nerves (PECS) I block to block the pectoral nerves. Even though PECS I and PECS II blocks have been adopted in clinical practice, we strongly believe that basic knowledge of their sensory and motor blocking capacity, and ultimately clinical efficacy, is lacking.

Dr. M S mentions the study of Dr. ELdeen, ${ }^{3}$ which raises many issues. Firstly, those authors studied patients with breast lumps scheduled for conservative breast surgery without axillary clearance. This less invasive breast surgery, which does not involve the pectoral muscles, does not require an interpectoral injection component. ${ }^{4}$ The possibility of performing this type of surgery under a PECS II block is anatomically reasonable if the tumor is not located too medially. Contrary to the statement in their discussion, the PECS II does not block the T2-T6 spinal nerves, and thus only their lateral cutaneous branches, and would therefore not be adequate for surgery on the anterior medial chest wall. Contrary to Dr. M S's statement, this area is not innervated by the pectoral nerves. The description of sensory testing in the methods section of Dr. ELdeen's study lacks a clear mention of where it was tested on the chest wall. We believe that they could not have obtained a sensory block in the parasternal area.

J. Desroches, MD, FRCPC

Department of Anesthesiology, Hôtel-Dieu de St Jérôme, St Jérôme, QC, Canada

M. Roy, MD ( $\varangle)$ · P. Beaulieu, MD, PhD, FRCA

Department of Anesthesiology, CHUM, Montreal, QC, Canada

e-mail: maxim.roy20@gmail.com
The study by Hetta and Rezk ${ }^{5}$ showed the superiority of the paravertebral block (PVB) over the pectoralis-serratus plane block (basically the PECS II without the interpectoral injection) for radical mastectomy. We believe, contrary to Dr. M S, that the superiority of the PVB comes, in part, from its ability to also block the anterior cutaneous branches of the intercostal nerves, which is not the case with the PECS II block. Radical mastectomy involves the pectoral muscles, thus interpectoral injection of the PECS II could theoretically be of benefit. Nevertheless, our own experience with these blocks (currently un-published data) indicates that a PECS I block is not beneficial for surgery involving the pectoral muscles.

Finally, we are aware of a paper from Ali Hassn et al. ${ }^{6}$ and should have explained why we did not include it in our paper. We believe, as others, ${ }^{3}$ that there is still a need to evaluate both PECS I and II blocks as described by Dr. Blanco. ${ }^{7}$ In the Ali Hassn et al. study, they used a PECS II block with a mixture of bupivacaine and dexmedetomidine $1 \mu \mathrm{g} \cdot \mathrm{kg}^{-1}$. The addition of dexmedetomidine to local anesthetic could have contributed, at least in part, to the efficacy of the PECS II block compared with placebo. They observed a significant reduction in intubation heart rate and blood pressure in the bupivacaine-dexmedetomidine group that they attributed to dexmedetomidine. In conclusion, we believe that more studies are needed to help determine the best clinical use of the PEC blocks.

Conflicts of interest None declared.

Editorial responsibility This submission was handled by Dr. Hilary P. Grocott, Editor-in-Chief, Canadian Journal of Anesthesia. 


\section{References}

1. MS R. Clarification on: "Pectoral nerves I block is associated with a significant motor blockade with no dermatomal sensory changes". Can J Anesth 2018; 65: this issue. DOI: https://doi. org/10.1007/s12630-018-1228-6.

2. Desroches J, Bellivau M, Bilodeau C, Landry M, Roy M, Beaulieu $P$. Pectoral nerves I block is associated with a significant motor blockade with no dermatomal sensory changes: a prospective volunteer randomized-controlled double-blind study. Can J Anesth 2018; 65: 806-12.

3. ELdeen HM. Ultrasound guided pectoral nerve blockade versus thoracic spinal blockade for conservative breast surgery in cancer breast: a randomized controlled trial. Egypt J Anaesth 2016; 32: 29-35.
4. Woodworth GE, Ivie RM, Nelson SM, Walker CM, Maniker RB. Perioperative breast analgesia: a qualitative review of anatomy and regional techniques. Reg Anesth Pain Med 2017; 42: 609-31.

5. Hetta DF, Rezk KM. Pectoralis-serratus interfascial plane block vs thoracic paravertebral block for unilateral radical mastectomy with axillary evacuation. J Clin Anesth 2016; 34: 91-7.

6. Hassn AM, Zanfaly HE, Biomy TA. Pre-emptive analgesia of ultrasound-guided pectoral nerve block II with dexmedetomidinebupivacaine for controlling chronic pain after modified radical mastectomy. Res Opin Anesth Intensive Care 2016; 3: 6-13.

7. Blanco $R$, Fajardo $M$, Parras Maldonado $T$. Ultrasound description of Pecs II (modified Pecs I): a novel approach to breast surgery. Rev Esp Anestesiol Reanim 2012; 59: 470-5. 